\title{
Determination of Metal Impurities in Carbon Nanotubes by Direct Solid Sampling Electrothermal Atomic Absorption Spectrometry
}

\author{
Paola A. Mello, Luiz Frederico Rodrigues, Matheus A. G. Nunes, Julio Cezar P. Mattos, \\ Edson I. Müller, Valderi L. Dressler and Erico M. M. Flores*
}

\author{
Departamento de Química, Universidade Federal de Santa Maria, 97105-900 Santa Maria-RS, Brazil \\ and Instituto Nacional de Ciência e Tecnologia de Bioanalítica, Campinas-SP, Brazil
}

\begin{abstract}
A determinação de $\mathrm{Al}, \mathrm{Cd}, \mathrm{Co}, \mathrm{Cr}, \mathrm{Cu}, \mathrm{Mg}, \mathrm{Mn}$ e $\mathrm{Pb}$ em nanotubos de carbono (CNTs) foi realizada por espectrometria de absorção atômica com atomização eletrotérmica e amostragem direta de sólidos (DSS-ET AAS, corretor de fundo com fonte de deutério). Foram avaliados os parâmetros de aquecimento, uso de Pd como modificador químico, possibilidade de calibração com soluções aquosas e massa máxima de amostra. Para comparação dos resultados as amostras foram analisadas por espectrometria de massa com plasma indutivamente acoplado (ICP-MS) e espectrometria de emissão óptica com plasma indutivamente acoplado (ICP OES) após decomposição por via úmida em sistema de alta pressão assistida por micro-ondas e também por combustão iniciada por micro-ondas. Não foram observadas diferenças significativas entre os resultados obtidos pelo método proposto e pelas outras técnicas. A exatidão também foi avaliada por comparação com resultados de análise por ativação neutrônica (NAA). A calibração foi possível com soluções de referência aquosas. Os sinais de fundo foram sempre inferiores a 0,02 (altura de pico) e o uso de modificador químico não foi necessário. O método proposto possibilitou a determinação de todos os analitos, com menores limites de detecção quando comparados com as outras técnicas.
\end{abstract}

Metal impurities ( $\mathrm{Al}, \mathrm{Cd}, \mathrm{Co}, \mathrm{Cr}, \mathrm{Cu}, \mathrm{Mg}, \mathrm{Mn}$ and $\mathrm{Pb}$ ) were determined in carbon nanotubes (CNTs) by direct solid sampling electrothermal atomic absorption spectrometry (DSS-ET AAS, deuterium lamp background corrector). Parameters as pyrolysis and atomization temperatures, use of Pd as chemical modifier, feasibility of calibration using aqueous standard solutions and maximum sample mass were investigated. Results obtained by the proposed method were compared with those obtained by neutron activation analysis (NAA) and also by inductively coupled plasma mass spectrometry (ICP-MS) and inductively coupled plasma optical emission spectrometry (ICP OES) after high-pressure microwave assisted wet digestion and microwave-induced combustion methods. No significant differences were observed between the results obtained by DSS-ET AAS, ICP-MS and ICP OES after both digestion methods and also by NAA. Calibration was performed using aqueous standards. Background signals were always lower than 0.02 (peak height) and no chemical modifier was used. The proposed method allowed the determination of all elements in CNTs with lower limits of detection in comparison with other techniques.

Keywords: carbon nanotubes, metal impurities, solid sampling, electrothermal atomic absorption spectrometry

\section{Introduction}

Since the advent of nanotechnology the development of new materials with a wide range of special properties has been performed for very different applications in almost all technological fields. With the discovery of carbon nanotubes (CNTs) by Iijima, ${ }^{1}$ this new class of nanomaterials provided unique chemical, mechanical and electronic properties. In

*e-mail: ericommf@gmail.com recent years, carbon nanotubes have received a growing interest in several fields as materials industry, electronics, medicine and also in analytical applications. ${ }^{2-7}$ Carbon nanotubes can be described as a kind of graphite structure which is based on benzene-type hexagonal rings of carbon atoms, rolled up in a nanoscale tube (diameter ranging from a few tenths to tens of nanometers). This nanomaterial can be defined as a single-wall carbon nanotube (SWCNT) and when additional graphene tubes are present around the core of a SWCNT, it is defined as a multi-wall carbon nanotube (MWCNT). ${ }^{8,9}$ 
During the synthesis of CNTs, generally by chemical vapor deposition, arc discharge or laser ablation, it is necessary the use of metallic catalysts and the most common ones are based on nickel, cobalt, iron, lanthanum or their combinations. ${ }^{2,8,9}$ In general, commercial carbon nanotubes must be submitted to a final processing step for the removal of amorphous carbon, residues of metallic catalysts and side products ${ }^{10}$ by chemical and physical methods. ${ }^{11,12}$ However, even after an acid washing step (the most common method for CNTs purification, e.g., $36 \mathrm{~h}$ at $80{ }^{\circ} \mathrm{C}$ using $\mathrm{HNO}_{3}$ ), metals are still present in relatively high levels because a significant part of them is sheathed by several graphite layers inside the CNTs structure. ${ }^{13,14}$ The presence of metal impurities can affect the physical, chemical and surface properties of CNTs making difficult their use for industrial applications..$^{5,9,11,12}$ In addition, the toxicity by inhalation and the risk assessment have been recently discussed in literature due to the increasing use of CNTs in medicine and related areas. ${ }^{15-18}$ Moreover, the presence of metal impurities can increase the potential risk of these materials. In this way, the development of methods for the determination of metallic elements in low concentration is strongly required for CNTs. ${ }^{10,11}$

The most common way of sample introduction using atomic spectrometric techniques is as aqueous solutions. However, the main problem concerning the determination of impurities in CNTs is the sample preparation step since these materials are extremely difficult to bring into solution in view of their stable structure. ${ }^{13,14}$ Recently, some methods for CNTs digestion have been discussed in literature. Microwave-assisted digestion using a mixture of nitric and perchloric acids ( $1 \mathrm{~h}$ heating) was applied before the determination of $\mathrm{Al}, \mathrm{Cr}, \mathrm{Fe}, \mathrm{Mo}$, and $\mathrm{Ni}$ by inductively coupled plasma optical emission spectrometry (ICP OES).${ }^{19}$ In another work, a digestion method of CNTs for metals determination by inductively coupled plasma mass spectrometry (ICP-MS) was recently proposed using a combination of dry ashing and wet digestion, with concentrated nitric acid and hydrogen peroxide for the determination of $\mathrm{Cr}, \mathrm{Mn}, \mathrm{Fe}, \mathrm{Co}, \mathrm{Ni}, \mathrm{Cu}, \mathrm{Zn}$ and $\mathrm{Mo}$, and results were compared with those obtained by neutron activation analysis (NAA). ${ }^{20}$ In the same work, it was also pointed out the possibility of using microwave-assisted digestion. However, only a very small sample mass $(20 \mathrm{mg})$ of MWCNT could be digested with concentrated nitric acid even by $30 \mathrm{~min}$ at $200{ }^{\circ} \mathrm{C} .{ }^{20}$

In spite of the relatively good results obtained using the previously described procedures, they are considered as time consuming (dry ashing) and required the use of concentrated reagents (wet digestion). As a consequence, they are prone to analyte losses or contamination and can result in generation of highly concentrated acid residues (specially wet digestion). It is also important to mention that incomplete digestion, high acid content (or the presence of perchloric and hydrochloric acids) in the digests can cause systematic errors for the determination using atomic spectrometric techniques. ${ }^{21,22}$

Recently, the determination of $\mathrm{Co}, \mathrm{Cr}, \mathrm{Cu}, \mathrm{Fe}, \mathrm{Mo}$, $\mathrm{Ni}$, and $\mathrm{Zn}$ by ICP-MS and ICP OES was evaluated after microwave-assisted digestion. Good results were found in comparison with those obtained by NAA. ${ }^{23}$ However, only $5 \mathrm{mg}$ of CNT samples were digested even using concentrated nitric acid and hydrogen peroxide by $45 \mathrm{~min}$ making difficult to obtain low limits of detection (LOD). In addition, nonspectral interferences caused by carbon residues in sample solution were reported. ${ }^{23}$ Microwaveinduced combustion (MIC) has been successfully applied for organic samples most of them considered hard to be digested using concentrated acids in closed systems. This method has been also recently proposed for the determination of $\mathrm{La}$ and $\mathrm{Ni}$ as catalyst residues by ICP OES, ${ }^{24}$ and for halogens determination by ICP-MS and ion chromatography. ${ }^{25}$ Despite the previously reported methods for CNTs digestion, some drawbacks can be pointed out as the low efficiency of decomposition and also the interferences that can be caused by the high acid concentration and/or residual carbon content. Moreover, the digestion step is generally associated with a significant dilution and sometimes a pre-concentration and/or matrix separation step might be employed spending more time and reagents. ${ }^{21,22,26}$

Owing to the limitations of wet digestion, several approaches have been considered for the development of reagent free digestion methods. On this aspect, NAA is one of the most powerful techniques for direct analysis of solid samples and it has been proposed for determination of trace elemental impurities in SWCNT and MWCNT. ${ }^{10}$ However, despite some advantages as high sensitivity and selectivity for many elements it requires a nuclear reactor that makes difficult its use for routine analysis. ${ }^{23}$ On the other hand, the direct analysis of solid samples has been proposed as an alternative in atomic absorption spectrometry. ${ }^{27-30}$

Direct solid sampling electrothermal atomic absorption spectrometry (DSS-ET AAS) has proven to be a highly worthwhile method for the analysis of several very difficult matrices to digest, as aluminum oxide, ${ }^{31}$ silicon carbide, ${ }^{32}$ silicon nitride, ${ }^{33}$ sand ${ }^{34}$ alumina based catalysts,${ }^{35}$ zirconium dioxide, ${ }^{36}$ boron nitride, ${ }^{37}$ polymers ${ }^{38}$ and graphite. ${ }^{32}$ Several advantages of DSS-ET AAS have been reported as the low risk of contamination and relatively small sample mass requirement. As the sample pretreatment 
step can be minimized or even excluded, this technique allows increasing the sample throughput and hence none or only very small amount of reagents are required. As a consequence, residues generation can be strongly reduced. In addition, the very low limits of detection and relative robustness make this technique suitable for trace element analysis for routine aplication. ${ }^{27,32,39-42}$

In the present study DSS-ET AAS was applied to the determination of eight elements $(\mathrm{Al}, \mathrm{Cd}, \mathrm{Co}, \mathrm{Cr}$, $\mathrm{Cu}, \mathrm{Mg}, \mathrm{Mn}$ and $\mathrm{Pb}$ ) in SWCNTs and MWCNTs. The operational parameters were evaluated in order to achieve feasible calibration using aqueous standards. For accuracy evaluation, the results obtained by DSS-ET AAS were compared with those obtained by ICP-MS and ICP OES after sample digestion and also with the results obtained by NAA.

\section{Experimental}

\section{Instrumentation}

All measurements were carried out with a Model AAS 5 EA atomic absorption spectrometer (Analytik Jena, Jena, Germany) equipped with a deuterium background correction system, a transversely heated graphite atomizer and an Model SSA 5 manual solid sample introduction system. Pyrolytically coated graphite tubes, platforms, hollow cathode lamps and deuterium lamp were supplied by Analytik Jena. A model M2P microbalance with resolution of $0.001 \mathrm{mg}$ (Sartorius, Göttingen, Germany) was used for sample weighing.

A microwave sample preparation system (Multiwave 3000, software version v1.27-Synt, Anton Paar, Graz, Austria) equipped with high-pressure quartz vessels (internal volume of $80 \mathrm{~mL}$, maximum operating temperature and pressure of $280^{\circ} \mathrm{C}$ and $80 \mathrm{bar}$, respectively) was used for high-pressure microwave-assisted wet digestion and for MIC digestion. Commercial combustion quartz holders (Anton Paar, part number 16427) were used for MIC.

Determination of metals after sample digestion was performed using an inductively coupled plasma mass spectrometer (PerkinElmer-SCIEX, Model Elan DRC II, Thornhill, Canada) equipped with a concentric nebulizer (Meinhard Associates, Golden, CO, USA), a cyclonic spray chamber (Glass Expansion, Inc., West Melbourne, Australia) and a quartz torch with a quartz injector tube ( $2 \mathrm{~mm}$ i.d.). Radiofrequency power was $1400 \mathrm{~W}$, plasma, auxiliary and nebulizer gas flow-rates were 15.0, 1.2 and $1.15 \mathrm{~L} \mathrm{~min}^{-1}$, respectively. Measurements were performed using ${ }^{114} \mathrm{Cd},{ }^{59} \mathrm{Co},{ }^{63} \mathrm{Cu},{ }^{55} \mathrm{Mn}$, and ${ }^{208} \mathrm{~Pb}$ isotopes. A simultaneous inductively coupled plasma optical emission spectrometer (Model Optima 4300 DV, PerkinElmer, Shelton, CT, USA) was also used for CNTs analysis. A concentric nebulizer and a cyclonic spray chamber (Glass Expansion Inc.) were used. The radiofrequency power was set at $1300 \mathrm{~W}$ and plasma gas flow rates were 15.0, 0.2 and $0.8 \mathrm{~L} \mathrm{~min}^{-1}$ for principal, auxiliary and nebulizer, respectively. The selected wavelengths were $396.152 \mathrm{~nm}$ (Al), $228.802 \mathrm{~nm}(\mathrm{Cd}), 228.616 \mathrm{~nm}(\mathrm{Co}), 267.716 \mathrm{~nm}(\mathrm{Cr})$, $327.396 \mathrm{~nm}(\mathrm{Cu}), 279.553 \mathrm{~nm}(\mathrm{Mg}), 257.611 \mathrm{~nm}(\mathrm{Mn})$ and $220.353 \mathrm{~nm}(\mathrm{~Pb})$. Instrumental parameters for ICP-MS and ICP OES measurements were selected following the instructions of the respective manufacturer ${ }^{43,44}$ Argon (99.996\%, White Martins - Praxair, São Paulo, SP, Brazil) was used for ICP-MS and ICP OES.

All statistical calculations, including one-way analysis of variance (ANOVA, $\mathrm{P}<0.05$ ), were performed using GraphPad InStat (GraphPad InStat Software Inc, Version $3.00,1997)$ software.

\section{Reagents and samples}

Water was distilled, deionized and purified in a Milli-Q system (18.2 M $\Omega \mathrm{cm}$, Millipore, Billerica, MA, USA). Analytical grade nitric acid (Merck, Darmstadt, Germany) was doubly distilled using a sub-boiling distillation system (model DuoPur, Milestone, Sorisole, Italy). Calibration standard solutions were daily prepared by serial dilution of single-element stock standard solutions (1000 $\mathrm{mg} \mathrm{L}^{-1}$ in $2 \% \mathrm{v} / \mathrm{v} \mathrm{HNO}_{3}$, Merck). Ammonium nitrate (Merck) was used as igniter for MIC method $\left(6 \mathrm{~mol} \mathrm{~L}^{-1}\right.$ solution in water).

Five commercial single and multi-wall carbon nanotube samples (named as CNT samples A to E) obtained by catalytic chemical vapor deposition with nickel catalysts were used in this study. Sample characteristics are shown in Table 1.

\section{Procedures}

For the proposed DSS-ET AAS method, test samples from 0.05 to $7 \mathrm{mg}$ were weighed directly onto the graphite platform using a microspatula and transferred to the graphite tube using the manual device for solid sample introduction. New graphite platforms were purified by applying consecutive heating cycles using an atomization temperature of $2600{ }^{\circ} \mathrm{C}$ until low and constant blank values (integrated absorbances lower than $0.002 \mathrm{~s}$ were achieved after two heating cycles). All determinations were carried out without any sample pretreatment. Blank values were determined by performing the complete analysis cycle including the transport of the empty platform from the 
Table 1. Characteristics of CNT samples used in this study ${ }^{a}$

\begin{tabular}{lcccc}
\hline Sample & Type & Minimum purity / $\%)$ & Outside diameter $/ \mathrm{nm}$ & Length / $\mu \mathrm{m}$ \\
\hline A & SWCNT & 99 & not informed & not informed \\
B & MWCNT & 95 & $20-40$ & $1-2$ \\
C & MWCNT & 95 & $20-40$ & $5-15$ \\
D & MWCNT & 90 & $10-30$ & $1-10$ \\
E & SWCNT & 98 & not informed & not informed \\
\hline
\end{tabular}

Information in Table 1 was provided by the manufacturer.

balance to atomizer. Calibration curves were obtained by manual pipetting different volumes of the respective aqueous standard solution onto the platform (from 2 to $20 \mu \mathrm{L}$ ). Integrated absorbance mode was used for the evaluation of absorption signals. Owing to the high vaporization temperatures of sample matrix, the cleanout step was shown to be inefficient for sample removal from platform. Sample residues from the graphite platform were easily removed using pressurized air and, as a result, the cleanout step was not necessary. Alternative lines and the use of Ar flow-rate during atomization step were selected when necessary to reduce the sensitivity of ET AAS for quantification for samples with higher analyte contents. Instrumental parameters and temperature programs are presented in Tables 2 and 3, respectively.

Results obtained by the proposed method for metals determination in CNTs were compared with those obtained by ICP-MS and ICP OES after sample digestion. Microwaveassisted wet digestion was used with $50 \mathrm{mg}$ of sample and $6 \mathrm{~mL}$ of concentrated nitric acid (maximum pressure and temperature were set at $80 \mathrm{bar}$ and $280{ }^{\circ} \mathrm{C}$, respectively). Microwave heating program was (i) $1000 \mathrm{~W}$ for $60 \mathrm{~min}$ (10 min ramp); and (ii) $0 \mathrm{~W}$ for $20 \mathrm{~min}$ for cooling step. Digestion of CNTs was also performed by MIC for

Table 2. Instrumental parameters used for the individual elements

\begin{tabular}{lcccccccc}
\hline & \multicolumn{9}{c}{ Element } \\
\cline { 2 - 8 } Parameter & $\mathrm{Al}$ & $\mathrm{Cd}$ & $\mathrm{Co}$ & $\mathrm{Cr}$ & $\mathrm{Cu}$ & $\mathrm{Mg}$ & $\mathrm{Mn}$ & $\mathrm{Pb}$ \\
\hline Wavelength / nm & $394.4^{\mathrm{a}}$ & 228.8 & $240.7 / 241.2^{\mathrm{a}}$ & $425.4^{\mathrm{a}}$ & $324.8 / 327.8^{\mathrm{a}}$ & $202.6^{\mathrm{a}}$ & 279.5 & 283.3 \\
Spectral bandpass / nm & 0.5 & 0.8 & 0.2 & 0.2 & 0.8 & 0.8 & 0.2 & 0.8 \\
HCL current / mA & 6 & 5 & 12 & 5 & 6 & 7 & 6 & 6 \\
\hline
\end{tabular}

${ }^{\mathrm{a}}$ wavelength used for less sensitive condition.

Table 3. Temperature program used for analysis of CNTs by DSS-ET AAS

\begin{tabular}{|c|c|c|c|c|c|}
\hline Step & & $\mathrm{T} /{ }^{\circ} \mathrm{C}$ & Heating rate $/\left({ }^{\circ} \mathrm{C} \mathrm{s}^{-1}\right)$ & Hold time / s & Argon flow-rate / $\left(\mathrm{L} \mathrm{min}^{-1}\right)$ \\
\hline Drying & & 130 & 10 & 30 & 0.5 \\
\hline \multirow[t]{8}{*}{ Pyrolysis } & $\mathrm{Al}$ & 1500 & 50 & 30 & 0.5 \\
\hline & $\mathrm{Cd}$ & 600 & 50 & 30 & 0.5 \\
\hline & Co & 1400 & 50 & 30 & 0.5 \\
\hline & $\mathrm{Cr}$ & 1400 & 50 & 30 & 0.5 \\
\hline & $\mathrm{Cu}$ & 1000 & 50 & 30 & 0.5 \\
\hline & $\mathrm{Mg}$ & 1200 & 50 & 30 & 0.5 \\
\hline & $\mathrm{Mn}$ & 1400 & 50 & 30 & 0.5 \\
\hline & $\mathrm{Pb}$ & 800 & 50 & 30 & 0.5 \\
\hline \multirow[t]{8}{*}{ Atomization } & $\mathrm{Al}$ & 2500 & 3000 & 6 & $0.5^{\mathrm{b}}$ \\
\hline & $\mathrm{Cd}$ & 1700 & 3000 & 6 & $0^{\mathrm{a}}$ \\
\hline & Co & 2500 & 3000 & 10 & $0^{\mathrm{a}}$ or $0.5^{\mathrm{b}}$ \\
\hline & $\mathrm{Cr}$ & 2500 & 3000 & 10 & $0.5^{\mathrm{b}}$ \\
\hline & $\mathrm{Cu}$ & 2400 & 3000 & 10 & $0^{\mathrm{a}}$ or $0.5^{\mathrm{b}}$ \\
\hline & $\mathrm{Mg}$ & 2300 & 3000 & 8 & $0.5^{\mathrm{b}}$ \\
\hline & $\mathrm{Mn}$ & 2300 & 3000 & 10 & $0.5^{\mathrm{b}}$ \\
\hline & $\mathrm{Pb}$ & 1900 & 3000 & 8 & $0^{\mathrm{a}}$ \\
\hline
\end{tabular}

Cleanout step was not applied. ainternal gas stop. ${ }^{b}$ parameter used for less sensitive condition (see Table 2). 
comparison of results. In this case, MIC was carried out according to previous works ${ }^{24,45}$ using $6 \mathrm{~mL}$ of concentrated nitric acid as absorbing solution, $50 \mu \mathrm{L}$ of a $6 \mathrm{~mol} \mathrm{~L}^{-1}$ $\mathrm{NH}_{4} \mathrm{NO}_{3}$ solution as igniter ${ }^{46}$ and 20 bar of $\mathrm{O}_{2}$ for digestion of $200 \mathrm{mg}$ of sample. For both digestion methods, samples were diluted with water up to $30 \mathrm{~mL}$ in polypropylene vials prior to analysis by ICP-MS and ICP OES.

One sample of CNT (sample C) was selected to be analyzed by NAA. Analysis was performed at Institute of Energetic and Nuclear Research (IPEN, Laboratório de Análise por Ativação Neutrônica, Comissão Nacional de Energia Nuclear, São Paulo, SP, Brazil) under a neutron flow of $3 \times 10^{12} \mathrm{ncm}^{2} \mathrm{~s}^{-1}$ for $8 \mathrm{~h}$. Gamma activity measurements were performed using a hyperpure Ge detector (GX 2020, Canberra) linked to a spectrometer. The radioisotopes measured were ${ }^{60} \mathrm{Co}$ at $1332.5 \mathrm{keV}(5.24$ years $),{ }^{51} \mathrm{Cr}$ at $320.10 \mathrm{keV}$ (27.8 days), ${ }^{66} \mathrm{Cu}$ at $1039.00 \mathrm{keV}$ (5.10 min), ${ }^{27} \mathrm{Mg}$ at $1014.40 \mathrm{keV}(9.45 \mathrm{~min})$ and ${ }^{56} \mathrm{Mn}$ at $1642.7 \mathrm{keV}$ (2.58 h).

\section{Results and Discussion}

\section{Pyrolysis and atomization curves}

Initially, pyrolysis and atomization curves for $\mathrm{Al}, \mathrm{Cd}$, $\mathrm{Co}, \mathrm{Cr}, \mathrm{Cu}, \mathrm{Mg}, \mathrm{Mn}$ and $\mathrm{Pb}$ in aqueous solutions and solid samples were established in order to select suitable conditions for each element. The main aspects considered for this evaluation were the repeatability of absorption profiles, sensitivity and background signal intensity. When the heating program was applied to solid CNT samples the highly refractory matrix remained on the platform practically unchanged even using temperatures up to $2600{ }^{\circ} \mathrm{C}$. As a consequence of the non volatilization of sample matrix, no significant gas-phase interference due to carbon compounds were observed. When analyzing both aqueous standard solutions or solid samples, background signals were always lower than 0.02 (peak height) for all the analytes. The maximum mass loss at $2600{ }^{\circ} \mathrm{C}$ was below $2 \%$ for all CNT samples. As performed in previous work and based on the thermally stable behavior of sample matrix, a cleanout step was considered as not necessary. ${ }^{47}$ Then, after the heating program the platform was removed from the graphite furnace and cleaned using a flow of pressurized air before the next weighing step as previously reported. ${ }^{32}$ No memory effects were observed for all the analytes including also carbide forming elements, such as Cr. This effect was evaluated by applying a subsequent heating program without the cleanout step and also matrix removing. However, no difference was observed when compared with the experiment with the removal of matrix after the atomization step.
The use of oxygen flow during the pyrolysis step was also evaluated. In these experiments pyrolysis was applied for $40 \mathrm{~s}$ and in the first $30 \mathrm{~s}$ an $\mathrm{O}_{2}$ flow-rate of $0.5 \mathrm{~L} \mathrm{~min}^{-1}$ was applied. When using oxygen the sample matrix (about $7 \mathrm{mg}$ ) was completely eliminated. However, no differences were observed in absorbance or absorption profile for the results with and without oxygen during pyrolysis. Then, in order to avoid the use of an additional gas and also to improve the tube and platform lifetime, the use of oxygen was not considered in this work for further experiments.

Based on these previous tests, pyrolysis and atomization temperatures for $\mathrm{Al}, \mathrm{Cd}, \mathrm{Co}, \mathrm{Cr}, \mathrm{Cu}, \mathrm{Mg}, \mathrm{Mn}$ and $\mathrm{Pb}$ were established based on the thermal behavior of aqueous standard solution and solid CNT matrix. Table 3 shows pyrolysis temperatures for CNT samples which are the maximum temperatures where no significant losses were observed for both standard solution and solid CNT sample. Pyrolysis temperatures ranged from $600{ }^{\circ} \mathrm{C}$ (for $\mathrm{Cd}$ ) up to $1500{ }^{\circ} \mathrm{C}$ (for Al). In general, analyte losses in CNT samples were observed in temperatures between 100 to $200{ }^{\circ} \mathrm{C}$ higher in comparison to the temperature where losses in aqueous standard solutions were observed. Atomization temperatures are also given in Table 3 and they ranged from $1700{ }^{\circ} \mathrm{C}$ (for $\mathrm{Cd}$ ) to $2500{ }^{\circ} \mathrm{C}$ (for $\mathrm{Al}, \mathrm{Co}$ and $\mathrm{Cr}$ ). For most of elements the selected atomization temperatures were comparable to the conditions used in previous work for a similar matrix (graphite) also without chemical modifiers and using the same model of equipment. ${ }^{32}$ Using the selected conditions, the platform lifetime was about 400 runs and for graphite tubes it was about 600 heating cycles.

\section{Analytical signals and calibration}

Signals for analytes atomized from aqueous standard solution and solid samples presented similar absorption profiles. Figure 1 shows, as an example, the $\mathrm{Pb}$ signals for aqueous standard solution and solid samples of CNTs.

It is possible to observe that analyte release from aqueous standard solution (peak a) is slightly faster than its release from sample matrix (peak c). When the standard solution was pipetted onto residual sample matrix (residue of sample remained after the complete heating program which was not removed after previous atomization step) the analyte release was also delayed (peak b). In Figure 1, peak $d$, is shown the analytical signal for the standard solution added to the CNT sample A. The highest sample mass that could be weighed in the graphite platform was $7 \mathrm{mg}$. From the respective signal for CNT sample B (peak e) it is possible to observe that higher sample masses resulted in delayed signals. However, results were considered not statistically different from those obtained with lower sample 


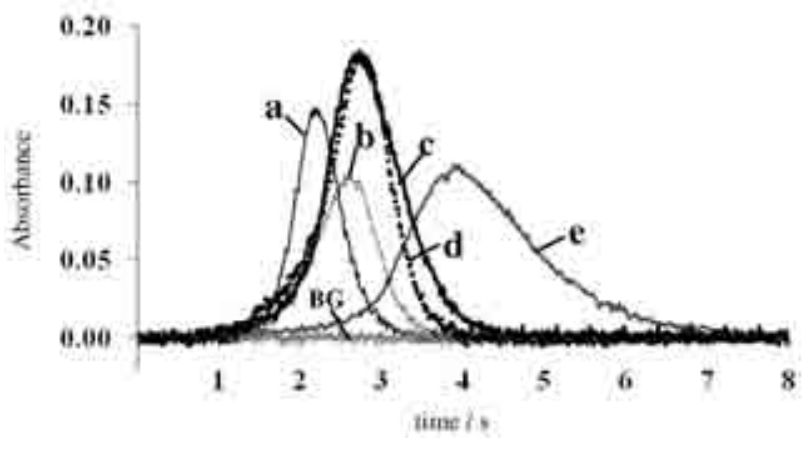

Figure 1. Atomic absorption signals for $\mathrm{Pb}$ obtained for aqueous standard solution and solid CNT samples and background signals (BG) for the same solid sample (for temperature programs see Table 3). a) $250 \mathrm{pg}$ $\mathrm{Pb}$ in aqueous standard solution, $\mathrm{A}_{\text {int }}=0.099 \mathrm{~s}$; b) $250 \mathrm{pg} \mathrm{Pb}$ pipetted onto $3.55 \mathrm{mg}$ of residual matrix remained after heating program for CNT sample A, $\mathrm{A}_{\text {int }}=0.099 \mathrm{~s}$; c) $530 \mathrm{pg} \mathrm{Pb}(3.63 \mathrm{mg}$ of CNT sample A), $\mathrm{A}_{\text {int }}=0.210 \mathrm{~s}$; d) $250 \mathrm{pg} \mathrm{Pb}$ pippeted onto $1.53 \mathrm{mg}$ CNT sample A $(220 \mathrm{pg} \mathrm{Pb}), \mathrm{A}_{\text {int }}=0.184 \mathrm{~s}(470 \mathrm{pg} \mathrm{Pb})$; e) $544 \mathrm{pg} \mathrm{Pb}$ (7.07 mg CNT sample $B), A_{\text {int }}=0.218 \mathrm{~s}$.

masses (ANOVA, $\mathrm{P}<0.05$ ). This behavior is generally observed for the analytes vaporization from solid samples and can be attributed to physical (diffusion) and chemical interactions of the elements with the matrix. Taking into account that no significant interferences were observed, this effect was not further investigated in the present work. A similar behavior was observed for other analytes.

For $\mathrm{Al}, \mathrm{Cd}, \mathrm{Co}$ and $\mathrm{Cu}$, atomized from sample matrix, the maximum peak height was about 0.4 to $0.7 \mathrm{~s}$ delayed in relation to the signal observed for aqueous solution. In case of $\mathrm{Mg}$, a similar behavior was observed regarding

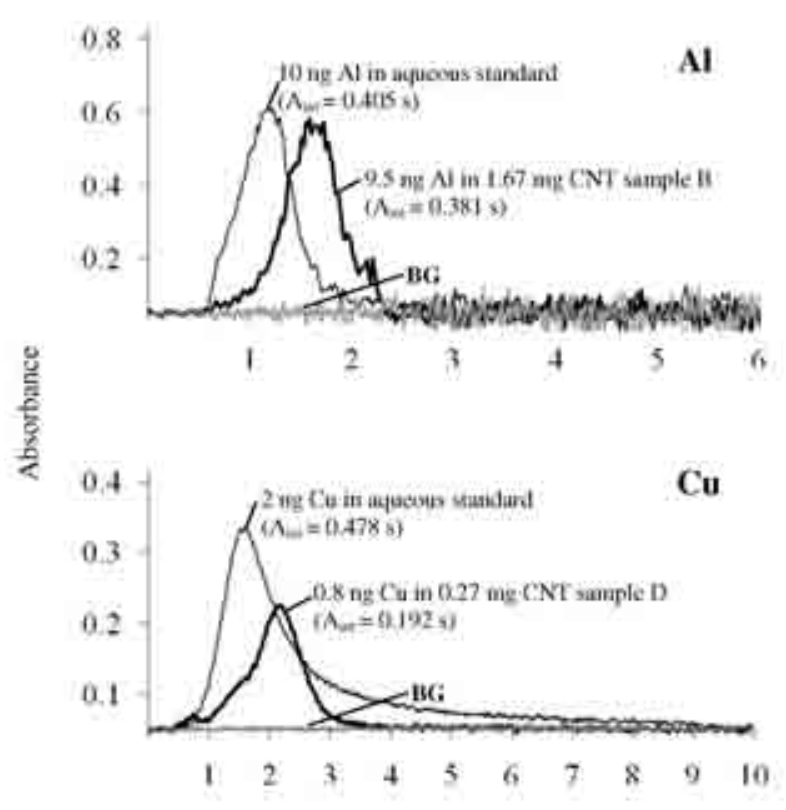

absorption profile for this analyte. No delay was observed for $\mathrm{Mg}$ when analyzing solid sample matrix. As example, Figure 2 shows the analytical signals for $\mathrm{Al}, \mathrm{Co}, \mathrm{Cu}$ and $\mathrm{Mg}$ in aqueous solution and solid CNT sample. It is important to mention that some differences between the transient signals in atomization from the CNT sample and from aqueous standard solution do not affect the accuracy by using integrated absorbance mode.

The only exception regarding to the analyte release from aqueous standard solution and solid sample matrix was observed for $\mathrm{Cr}$. In this case (Figure 3 ) it was observed

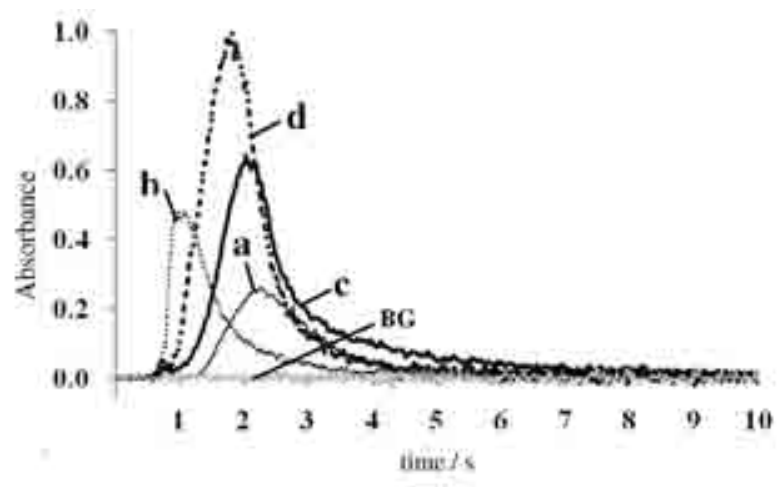

Figure 3. Atomic absorption signals for $\mathrm{Cr}$ obtained for aqueous standard solutions and solid CNT samples and background signals (BG) for the same solid sample (for temperature programs see Table 3). a) $1 \mathrm{ng} \mathrm{Cr}$ in aqueous standard solution, $\mathrm{A}_{\text {int }}=0.496 \mathrm{~s}$; b) $1 \mathrm{ng} \mathrm{Cr}$ pipetted onto $0.52 \mathrm{mg}$ of residual sample matrix remained after heating program for CNT sample B, $A_{\text {int }}=0.489 \mathrm{~s}$; c) $2.1 \mathrm{ng} \mathrm{Cr}(0.47 \mathrm{mg}$ of CNT sample B), $\left.\mathrm{A}_{\mathrm{int}}=1.030 \mathrm{~s} ; \mathrm{d}\right) 1 \mathrm{ng}$ Cr pippeted onto $0.33 \mathrm{mg}$ CNT sample $\mathrm{B}(1.5 \mathrm{ng} \mathrm{Cr})$, $\mathrm{A}_{\text {int }}=1.196 \mathrm{~s}(2.5 \mathrm{ng} \mathrm{Pb})$.
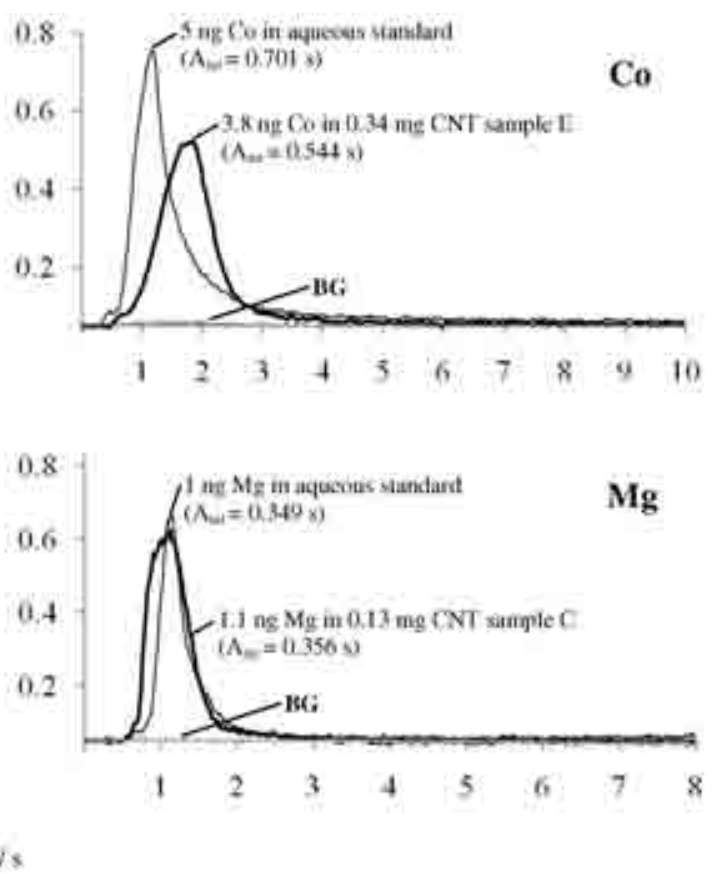

Figure 2. Atomic absorption signals for $\mathrm{Al}, \mathrm{Co}, \mathrm{Cu}$, and $\mathrm{Mg}$ obtained for aqueous standard solutions (-) and solid CNT samples (—) and background signals (BG). (For temperature programs see Table 3). 
a faster release from sample matrix (peak b) when it is compared to aqueous solution (peak a). For both signals $b$ and $\mathrm{d}$ spikes of aqueous solutions were added to residual matrix (after atomization) or to the CNT matrix (previously to heating program), respectively. For these signals it is possible to observe that the peak appearance starts before the correspondent to aqueous standard (peak a) or to the normal $\mathrm{Cr}$ content in CNT sample (peak c). It can be explained, as expected, by the similar volatility of $\mathrm{Cr}$ from spikes.

\section{Chemical modifier}

The necessity of using a chemical modifier was also investigated in this work in order to evaluate the thermal behavior of sample matrix and analyte atomization. Palladium solution (correspondent to $5 \mu \mathrm{g} \mathrm{Pd}$ ) was added directly on the solid sample after the weighing step on the graphite platform. No differences were observed related to the absorption profile and integrated area with or without the use of Pd. However, for all the analytes an increase in pyrolysis temperature was possible with Pd for both aqueous standard solution and solid CNTs. All signals were completely recorded within the selected integration time with and without chemical modifier. No improvement in sensitivity was found when using Pd. In addition, background signals were always lower than 0.02 (peak height) with or without Pd. Therefore, in order to simplify the analytical method the use of chemical modifier was considered as not necessary in the present work.

\section{Analysis of carbon nanotube samples}

In general, analysis of solid materials has been performed using calibration with aqueous standard solutions. ${ }^{33,34,36,40-42}$ Sometimes, solid reference materials can be required or even it could be necessary to add the standard solution onto the residual matrix remaining from the previous sample run. ${ }^{47}$ One of the main requirements for the development of a calibration method using aqueous standard solutions is that when analyzing solid samples the matrix effect on the absorbance signal is negligible. In order to verify this effect, characteristic masses were determined with the aqueous standard solution in the absence and in the presence of CNT solid matrix. This evaluation was performed for all the CNT samples. About $7 \mathrm{mg}$ of sample were weighed onto the sample platform and the selected heating program was applied (according to Table 3). After finishing the DSS-ET AAS heating program the sample remained practically unchanged in graphite platform. Then, aqueous standard solution was added onto the residual matrix in order to observe the absorption profile for all analytes. Characteristic masses obtained for all investigated elements are presented in Table 4.

According to the results obtained from this study no significant difference was found between the characteristic masses obtained by pipetting the standard solution onto graphite platform with or without residual sample matrix for all elements. The absorption profile and transiency were delayed in sample matrix as discussed previously, but no significant change in sensitivity was observed (see Figures 1 and 2). Thus, calibration could be performed for all the analytes using aqueous standard solution added directly onto the graphite platform without sample matrix.

As no certified reference material is available for metals in CNTs, the accuracy of the proposed DSS-ET AAS method was checked by comparison of the results with those obtained by high-pressure microwave-assisted wet digestion or MIC followed by analysis by ICP-MS and ICP OES. Due to the interferences that could be observed for elements with $\mathrm{m} / \mathrm{z}$ lower than 80 using quadrupole ICP-MS. Results for $\mathrm{Al}, \mathrm{Cr}$ and $\mathrm{Mg}$ were obtained only by ICP OES. Cadmium, $\mathrm{Co}, \mathrm{Cu}, \mathrm{Mn}$ and $\mathrm{Pb}$ were determined by both ICP-MS and ICP OES and when their concentration was higher than the LOD no statistical difference (t-test at the significance level of $\mathrm{P}=0.05$ ) was observed. Table 5 shows the results obtained by the proposed DSS-ET AAS method and by ICP-MS (for $\mathrm{Cd}, \mathrm{Co}, \mathrm{Cu}, \mathrm{Mn}$ and $\mathrm{Pb}$ ) and ICP OES (for $\mathrm{Al}, \mathrm{Mg}$ and $\mathrm{Cr}$ ) after two different sample digestion methods.

No statistical difference (ANOVA, P < 0.05) was observed for the results obtained by DSS-ET AAS and ICP-MS after digestion by both high-pressure microwave-assisted wet digestion and MIC. In addition,

Table 4. Characteristic masses obtained for aqueous standard solution with or without residual sample matrix

\begin{tabular}{|c|c|c|c|c|c|c|c|c|}
\hline \multirow{2}{*}{ Condition } & \multicolumn{8}{|c|}{ Characteristic mass / pg } \\
\hline & $\mathrm{Al}$ & $\mathrm{Cd}$ & Co & $\mathrm{Cr}$ & $\mathrm{Cu}$ & $\mathrm{Mg}$ & $\mathrm{Mn}$ & $\mathrm{Pb}$ \\
\hline Aqueous standard solution & $109^{\mathrm{a}}$ & 0.6 & $8.6 / 31.4^{\mathrm{a}}$ & $8.9^{\mathrm{a}}$ & $5.1 / 18.4^{\mathrm{a}}$ & $12.6^{\mathrm{a}}$ & 2.4 & 11.1 \\
\hline $\begin{array}{l}\text { Aqueous standard solution added onto the residual } \\
\text { CNT residual matrix }\end{array}$ & $111^{\mathrm{a}}$ & 0.6 & $8.4 / 32.0^{\mathrm{a}}$ & $9.0^{\mathrm{a}}$ & $5.3 / 18.6^{\mathrm{a}}$ & $12.2^{\mathrm{a}}$ & 2.5 & 11.1 \\
\hline
\end{tabular}

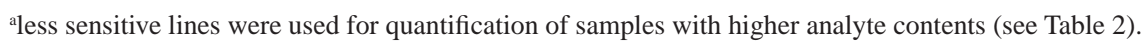


Table 5. Results obtained for analysis of carbon nanotube samples by DSS-ET AAS ( $\mathrm{n} \geq 6$ ) and comparison with those obtained by ICP-MS after highpressure microwave-assisted wet digestion $(n=3)$ and microwave-induced combustion $(n=3)$

\begin{tabular}{|c|c|c|c|c|c|c|c|}
\hline \multirow[t]{2}{*}{ Analyte } & \multirow[t]{2}{*}{ Sample } & \multicolumn{2}{|c|}{ DSS-ET AAS } & \multicolumn{2}{|c|}{ Microwave-assisted wet digestion } & \multicolumn{2}{|c|}{ Microwave-induced combustion } \\
\hline & & mean $\pm \mathrm{sd}$ & LOD & mean $\pm \mathrm{sd}$ & LOD & mean $\pm \mathrm{sd}$ & LOD \\
\hline \multirow[t]{5}{*}{$\mathrm{Al} /\left(\mu \mathrm{g} \mathrm{g}^{-1}\right)^{\mathrm{a}}$} & $\mathrm{A}$ & $114 \pm 9$ & 0.12 & $104 \pm 7$ & $1.50^{\mathrm{a}}$ & $117 \pm 5$ & $0.40^{\mathrm{a}}$ \\
\hline & $\mathrm{B}$ & $5.70 \pm 0.83$ & & $5.19 \pm 0.72$ & & $5.46 \pm 0.44$ & \\
\hline & $\mathrm{C}^{\mathrm{b}}$ & $7.53 \pm 1.08$ & & $7.25 \pm 0.96$ & & $6.82 \pm 0.48$ & \\
\hline & $\mathrm{D}$ & $392 \pm 36$ & & $406 \pm 24$ & & $407 \pm 38$ & \\
\hline & $\mathrm{E}$ & $89.5 \pm 7.1$ & & $83.8 \pm 5.9$ & & $91.1 \pm 4.2$ & \\
\hline \multirow[t]{5}{*}{$\mathrm{Cd} /\left(\mathrm{ng} \mathrm{g}^{-1}\right)$} & A & $1.82 \pm 0.31$ & 0.15 & $<120$ & 120 & $<30$ & 30 \\
\hline & $\mathrm{B}$ & $\mathrm{ND}^{\mathrm{c}}$ & & $19370 \pm 600$ & & $18490 \pm 311$ & \\
\hline & $\mathrm{C}^{\mathrm{b}}$ & $1.35 \pm 0.22$ & & $<120$ & & $<30$ & \\
\hline & $\mathrm{D}$ & $4.50 \pm 0.69$ & & $<120$ & & $<30$ & \\
\hline & $\mathrm{E}$ & $1.29 \pm 0.19$ & & $<120$ & & $<30$ & \\
\hline \multirow[t]{5}{*}{$\mathrm{Co} /\left(\mu \mathrm{g} \mathrm{g}^{-1}\right)$} & A & $0.40 \pm 0.05$ & 0.022 & $0.41 \pm 0.05$ & 0.15 & $0.38 \pm 0.04$ & 0.04 \\
\hline & $\mathrm{B}$ & $20.8 \pm 1.4$ & & $22.2 \pm 0.8$ & & $22.1 \pm 1.5$ & \\
\hline & $\mathrm{C}^{\mathrm{b}}$ & $11.6 \pm 1.0$ & & $10.7 \pm 0.4$ & & $10.1 \pm 0.6$ & \\
\hline & $\mathrm{D}$ & $0.91 \pm 0.10$ & & $0.81 \pm 0.08$ & & $0.80 \pm 0.07$ & \\
\hline & $\mathrm{E}$ & $10.9 \pm 0.8$ & & $10.1 \pm 0.6$ & & $11.1 \pm 0.4$ & \\
\hline \multirow[t]{5}{*}{$\mathrm{Cu} /\left(\mu \mathrm{g} \mathrm{g}^{-1}\right)$} & A & $9.95 \pm 1.02$ & 0.006 & $10.7 \pm 1.4$ & 0.60 & $10.3 \pm 0.9$ & 0.15 \\
\hline & B & $0.17 \pm 0.02$ & & $<0.6$ & & $<0.15$ & \\
\hline & $\mathrm{C}^{\mathrm{b}}$ & $0.09 \pm 0.01$ & & $<0.6$ & & $<0.15$ & \\
\hline & $\mathrm{D}$ & $3.19 \pm 0.33$ & & $2.71 \pm 0.22$ & & $3.16 \pm 0.15$ & \\
\hline & $\mathrm{E}$ & $6.30 \pm 0.31$ & & $6.69 \pm 0.34$ & & $6.28 \pm 0.20$ & \\
\hline \multirow[t]{5}{*}{$\mathrm{Cr} /\left(\mu \mathrm{g} \mathrm{g}^{-1}\right)^{\mathrm{a}}$} & A & $10.9 \pm 1.2$ & 0.05 & $10.6 \pm 1.4$ & $0.80^{\mathrm{a}}$ & $10.2 \pm 0.4$ & $0.20^{\mathrm{a}}$ \\
\hline & $\mathrm{B}$ & $4.68 \pm 0.56$ & & $4.14 \pm 0.64$ & & $4.96 \pm 0.33$ & \\
\hline & $\mathrm{C}^{\mathrm{b}}$ & $1.16 \pm 0.17$ & & $0.96 \pm 0.09$ & & $1.20 \pm 0.12$ & \\
\hline & $\mathrm{D}$ & $13.2 \pm 1.4$ & & $11.7 \pm 0.5$ & & $13.7 \pm 1.5$ & \\
\hline & $\mathrm{E}$ & $7.21 \pm 0.44$ & & $7.32 \pm 0.40$ & & $6.91 \pm 0.32$ & \\
\hline \multirow[t]{5}{*}{$\mathrm{Mg} /\left(\mu \mathrm{g} \mathrm{g}^{-1}\right)^{\mathrm{a}}$} & A & $5.54 \pm 0.38$ & 0.02 & $5.93 \pm 0.43$ & $0.60^{\mathrm{a}}$ & $6.28 \pm 0.40$ & $0.15^{\mathrm{a}}$ \\
\hline & $\mathrm{B}$ & $13.0 \pm 1.9$ & & $13.1 \pm 0.9$ & & $13.4 \pm 1.1$ & \\
\hline & $\mathrm{C}^{\mathrm{b}}$ & $8.88 \pm 0.79$ & & $9.33 \pm 0.52$ & & $9.07 \pm 0.73$ & \\
\hline & $\mathrm{D}$ & $5.53 \pm 0.48$ & & $5.56 \pm 0.42$ & & $5.03 \pm 0.49$ & \\
\hline & $\mathrm{E}$ & $10.1 \pm 0.8$ & & $9.81 \pm 0.77$ & & $10.6 \pm 0.6$ & \\
\hline \multirow[t]{5}{*}{$\mathrm{Mn} /\left(\mu \mathrm{g} \mathrm{g}^{-1}\right)$} & A & $1.78 \pm 0.11$ & 0.008 & $1.74 \pm 0.13$ & 0.15 & $1.67 \pm 0.08$ & 0.04 \\
\hline & $\mathrm{B}$ & $0.67 \pm 0.05$ & & $0.64 \pm 0.02$ & & $0.67 \pm 0.04$ & \\
\hline & $\mathrm{C}^{\mathrm{b}}$ & $0.23 \pm 0.03$ & & $0.20 \pm 0.03$ & & $0.18 \pm 0.02$ & \\
\hline & $\mathrm{D}$ & $2.93 \pm 0.17$ & & $2.82 \pm 0.15$ & & $2.80 \pm 0.06$ & \\
\hline & $\mathrm{E}$ & $0.24 \pm 0.03$ & & $0.23 \pm 0.03$ & & $0.22 \pm 0.02$ & \\
\hline \multirow[t]{5}{*}{$\mathrm{Pb} /\left(\mathrm{ng} \mathrm{g}^{-1}\right)$} & A & $157 \pm 20$ & 3 & $134 \pm 20$ & 120 & $160 \pm 10$ & 30 \\
\hline & $\mathrm{B}$ & $77.2 \pm 15.7$ & & $92.0 \pm 10.2$ & & $101 \pm 13$ & \\
\hline & $\mathrm{C}^{\mathrm{b}}$ & $90.2 \pm 5.8$ & & $80.5 \pm 10.8$ & & $98.1 \pm 11.3$ & \\
\hline & $\mathrm{D}$ & $5419 \pm 420$ & & $4710 \pm 360$ & & $5040 \pm 330$ & \\
\hline & $\mathrm{E}$ & $1847 \pm 124$ & & $1911 \pm 116$ & & $1820 \pm 95$ & \\
\hline
\end{tabular}

Results for $\mathrm{Al}, \mathrm{Cr}$ and $\mathrm{Mg}$ after digestion were obtained by ICP OES. ${ }^{\mathrm{b}}$ Results obtained by NAA: $10.85 \pm 0.12 \mu \mathrm{g} \mathrm{g}^{-1}(\mathrm{Co}), 0.90 \pm 0.16 \mu \mathrm{g} \mathrm{g}{ }^{-1}(\mathrm{Cr}),<88 \mu \mathrm{g} \mathrm{g}{ }^{-1}$ $(\mathrm{Cu}),<689 \mu \mathrm{g} \mathrm{g} \mathrm{g}^{-1}(\mathrm{Mg}), 0.22 \pm 0.01 \mu \mathrm{g} \mathrm{g}^{-1}(\mathrm{Mn})$. Al, $\mathrm{Cd}$ and Pb were not determined by NAA. ${ }^{\mathrm{c}} \mathrm{ND}=$ not determined.

the results obtained by the proposed method for $\mathrm{Co}, \mathrm{Cr}, \mathrm{Cu}$, $\mathrm{Mg}$ and $\mathrm{Mn}$ in CNT sample $\mathrm{C}$ were also compared with the results obtained by NAA (see footnotes in Table 5). Aluminum, $\mathrm{Cd}$ and $\mathrm{Pb}$ were not determined by NAA. For
$\mathrm{Co}, \mathrm{Cr}$ and $\mathrm{Mn}$, no significant difference was observed between the results obtained by the proposed method and those obtained by NAA (results obtained by NAA were lower than $\mathrm{LOD}$ for $\mathrm{Mg}$ and $\mathrm{Cu}$ ). For $\mathrm{Mg}$ the result obtained 
by DSS-ET AAS was in agreement with the result obtained using digestion methods. For $\mathrm{Cu}$ all the results (NAA and ICP-MS after both digestion methods) were lower than the LOD with the exception of the result obtained by the proposed DSS-ET AAS method. For this sample the use of spikes was the only alternative to evaluate the accuracy (recovery better than $98 \%$ ).

For all elements in Table 5, relative standard deviations (RSDs) for DSS-ET AAS were between $4.9 \%$ (for $\mathrm{Cu}$ in CNT sample E) to $14.7 \%$ (for Cd in CNT sample A). The only exception was Cd in CNT samples A, C and D (17.0, 16.3 and $15.3 \%$, respectively), and $\mathrm{Pb}$ in sample $\mathrm{B}$ (20.3\%). It is important to mention that these higher RSDs were obtained only for $\mathrm{Cd}$ and $\mathrm{Pb}$ which were in ng g-1 level. Results obtained by ICP-MS with previous digestion by high-pressure microwave-assisted wet digestion and MIC showed RSD in the range of 3.1\% (for $\mathrm{Cd}$ in CNT sample B which is in $\mathrm{mg} \mathrm{kg}^{-1}$ level) to $15.5 \%$ (for $\mathrm{Cr}$ in sample $\mathrm{B}$ ) and $1.7 \%$ (also for $\mathrm{Cd}$ in sample $\mathrm{B}$ ) to $16.8 \%$ (for $\mathrm{Mn}$ in sample $\mathrm{A}$ ), respectively. For $\mathrm{Cd}$ in CNT sample B it was not possible to use DSS-ET AAS due to the high concentration. In general, atomic absorption spectrometry presents limited linear working ranges for most elements. ${ }^{28}$ The analysis of solid samples containing high analyte concentrations is limited in this case by the minimum sample amount applicable and by the relative sensitivity of available spectral lines. Moreover, solid samples are very difficult to dilute and assuring suitable homogeneity. This possibility is also restricted by the low availability of very pure solid diluents with similar particle size distribution and mainly by physical characteristics of the diluents that can be different of the matrix to be diluted. In this way, some approaches for sensitivity decreasing sometimes have to be applied to direct solid sampling analysis for relatively high analyte concentrations, as the use of alternative lines and inert gas flow-rate during atomization. In this work, these approaches were used when necessary as can be seen in conditions reported in Tables 2 and 3 (both approaches were used for $\mathrm{Al}, \mathrm{Cr}$ and $\mathrm{Mg}$ ).

Regarding to the health concern, results in Table 5 show the necessity to determine metal contaminants in CNT samples once some elements, as $\mathrm{Cd}$ and $\mathrm{Pb}$ were found at relatively high level. Other elements, such as $\mathrm{Al}, \mathrm{Cu}, \mathrm{Co}$ and $\mathrm{Mg}$, were found in $\mathrm{m} \mathrm{kg}^{-1}$ levels in some samples and, depending on the industrial application, they can affect the properties of the final materials. ${ }^{9,10,12}$

In Table 5 it is possible to see that DSS-ET AAS allowed LODs ranging from 2 to 200 times lower than the values obtained with digestion methods even using ICP-MS which is generally considered as a powerful technique for the determination of trace elements. Values for LOD were calculated for the maximum applicable sample mass for each method that was 7, 50 and $200 \mathrm{mg}$ for DSS-ET AAS, microwave-assisted wet digestion and MIC, respectively. Using the wet digestion method, solid residues of non decomposed material remained for sample masses higher than $50 \mathrm{mg}$, which is considered a disadvantage for obtaining low LODs.

In the present work RSDs were relatively low for results obtained by DSS-ETAAS showing that the investigated materials can be considered as homogeneous even using sample masses limited to $7 \mathrm{mg}$ due to the platform sample mass capacity. It is important to mention that the proposed DSS-ET AAS method does not require a previous time consuming sample treatment then allowing the reduction of analyte losses and contamination risks. On the other hand, residues generation and manipulation of concentrated acids conventionally used in decomposition methods can be avoided in DSS-ET AAS.

\section{Conclusions}

The increasing use of carbon nanotubes especially in industry and medicine requires the development of suitable analytical methods for the determination of metal impurities in this kind of material. The proposed DSS-ET AAS method showed to be suitable for this purpose. Eight elements could be determined in CNTs with calibration performed using aqueous standard solutions, without the use of chemical modifiers and with a relatively high sample mass $(7 \mathrm{mg})$. Especially when considering analysis time, simplicity, reagents consumption, residues generation and achievable low limits of detection, DSS-ET AAS can be considered as an advantageous method for quality control of metal impurities in CNTs.

\section{Supplementary Information}

Supplementary information data (Figures S1-S3) are available free of charge at http://jbcs.sbq.org.br as a PDF file.

\section{Acknowledgments}

The authors are grateful to Conselho Nacional de Desenvolvimento Científico e Tecnólogico, Instituto Nacional de Ciência e Tecnologia de Bioanalítica (INCTBio/CNPq (Process No. 573672/2008-3), Coordenação de Aperfeiçoamento de Pessoal de Nível Superior (CAPES) and Fundação de Amparo à Pesquisa do Estado do Rio Grande do Sul (FAPERGS) for supporting this study. 


\section{References}

1. Iijima, S.; Nature 1991, 354, 56.

2. Burchell, T. D.; Carbon Materials for Avanced Technologies; Elsevier Science: Oxford, 1999.

3. Lin, Y.; Taylor, S.; Li, H.; Fernando, K. A. S.; Qu, L.; Wang, W.; Gu, L.; Zhou, B.; Sun, Ya-P.; J. Mater. Chem. 2004, 14, 527.

4. Misra, R.; Acharya, S.; Sahoo, S. K.; Drug Discovery Today 2010, 15, 842 .

5. Trojanowicz, M.; Trends Anal. Chem. 2006, 25, 480.

6. Merkoçi, A.; Microchim. Acta 2006, 152, 157.

7. Valcárcel, M.; Cárdenas, S.; Simonet, B. M.; Moliner-Martínez, Y.; Lucena, R.; Trends Anal. Chem. 2008, 27, 34.

8. Dresselhaus, M. S.; Dresselhaus, G.; Eklund, P. C; Science of Fullerenes and Carbon Nanotubes; Academic Press: San Diego, 1996.

9. Tasis, D.; Tagmatarchis, N.; Bianco, A.; Prato, M.; Chem. Rev. 2006, 106, 1105.

10. Braun, T.; Rausch, H.; Biró, L. P.; Konya, Z.; Kiricsi, I.; J. Radioanal. Nucl. Chem. 2004, 262, 31.

11. Hou, P.-X.; Liu, C.; Cheng, H.-M.; Carbon 2008, 46, 2003.

12. Ismail, A. F.; Goh, P. S.; Tee, J. C.; Sanip, S. M.; NANO 2008 , 3,127 .

13. Pumera, M.; Langmuir 2007, 23, 6453.

14. Banks, C. E.; Crossley, A.; Salter, C.; Wilkins, S. J.; Compton, R. G.; Angew. Chem., Int. Ed. 2006, 45, 2533.

15. Liu, X.; Guo, L.; Morris, D.; Kane, A. B.; Hurt, R. H.; Carbon 2008, 46, 489.

16. Dawan, A.; Sharma, V.; Anal. Bioanal. Chem. 2010, 398, 589.

17. Lam, C. W.; James, J. T.; McCluskey, R.; Arepalli, S.; Hunter, R. L.; Crit. Rev. Toxicol. 2006, 36, 189.

18. Hurt, R. H.; Monthioux, M.; Kane, A. B.; Carbon 2006, 44, 1028.

19. Ishikuro, M.; Sato, Y.; Tohji, K.; Wagatsuma, K.; Bunseki Kagaku 2006, 55, 117.

20. Ge, C.; Lao, F.; Li, Wri, Chen, C.; Qiu, Y.; Mao, X.; Li, Bai.; Chai, Z.; Zhao, Y.; Anal. Chem. 2008, 80, 9426.

21. Todolí, J.-L.; Mermet, J.-M.; Spectrochim. Acta, Part B 1999, $54,895$.

22. Matusiewicz, H. In Comprehensive Analytical Chemistry. Sample Preparation for Trace Element Analysis; Mester , Z.; Sturgeon, R., eds.; Elsevier: Amsterdam, 2003, ch. 6.

23. Yang, K. X.; Kitto, M. E.; Orsini, J. P.; Swami, K.; Beach, S. E.; J. Anal. At. Spectrom. 2010, 25, 1290.

24. Mortari, S. R.; Cocco, C. R.; Bartz, F. R.; Dressler, V. L.; Flores, E. M. M.; Anal. Chem. 2010, 82, 4298.

25. Pereira, J. S. F.; Antes, F. G.; Diehl, L. O.; Knorr, K. L.; Mortari, S. R.; Dressler, V. L.; Flores, E. M. M.; J. Anal. At. Spectrom. 2010, 25, 1268.

26. Trevizan, L. C.; Donati, G. L.; Nogueira, A. R. A.; Nóbrega, J. A. In Trends in Sample Preparation; Arruda, M. A. Z. ed; Nova Science Publishers: New York, 2006, ch. 2.
27. Kurfürst, U.; Solid Sample Analysis - Direct and Slurry Sampling using GF-AAS and ETV-ICP; Springer: Berlin, 1998.

28. Welz, B.; Sperling, M.; Atomic Absorption Spectrometry; $3^{\text {rd }}$ ed.; Wiley-VCH: Weinheim, 1999.

29. Flores, E. M. M.; Costa, A. B.; Barin, J. S.; Dressler, V. L.; Paniz, J. N. G.; Martins, A. F.; Spectrochim. Acta, Part B 2001, $56,1875$.

30. Flores, E. M. M.; Paniz, J. N. G.; Saidelles, A. P. F.; Müller, E. I.; Costa, A. B.; J. Anal. At. Spectrom. 2003, 18, 769.

31. Lucic, M.; Krivan, V.; Fresenius J. Anal. Chem. 1998, 13, 1133.

32. Schäffer, U.; Krivan, V.; Fresenius J. Anal. Chem. 2001, 371, 859.

33. Mattos, J. C. P.; Flores, E. M. M.; Krivan V.; J. Anal. At. Spectrom. 2008, 23, 931.

34. Silva, C. S.; Nomura, C. S.; Nóbrega, J. A.; Oliveira, P. V.; Microchim. Acta 2008, 161, 109.

35. Rodrigues, L. F.; Mattos, J. C. P.; Dressler, V. L.; Pozebon, D.; Flores, E. M. M.; Spectrochim. Acta, Part B 2007, 62, 933.

36. Krivan, V.; Janickova, P.; Anal. Bioanal. Chem. 2005, 382, 1949.

37. Barth, P.; Hassler, J.; Kudrik, I.; Krivan, V.; Spectrochim. Acta, Part B 2007, 62, 924.

38. Resano, M.; Briceño, J.; Belarra, M. A.; Spectrochim. Acta, Part B 2009, 64, 520.

39. Belarra, M. A.; Resano, M.; Vanhaecke, F.; Moens, L.; Trends Anal. Chem. 2002, 21, 828.

40. Vale, M. G. R; Oleszezuk, N.; Santos, W. N. L.; Appl. Spectrosc. Rev. 2006, 41, 377.

41. Nomura, C. S.; Oliveira, P. V. In Trends in Sample Preparation; Arruda, M. A. Z. ed; Nova Science Publishers: New York, 2006, ch. 1.

42. Nomura, C. S.; Silva, C. S.; Oliveira, P. V.; Quim. Nova 2008, 31,104

43. PerkinElmer-SCIEX; Elan Version 3.0, Software Guide, 1006920 A, Thornhill, Canada, 2003.

44. Optima 4000 Series Hardware Guide, 0993-6376, Shelton, USA, 2002.

45. Duarte, F. A.; Pereira, J. S. F.; Barin, J. S.; Mesko, M. F.; Dressler, V. L.; Flores, E. M. M.; Knapp, G.; J. Anal. At. Spectrom. 2009, 24, 224.

46. Pereira, J. S. F.; Diehl, L. O.; Duarte, F. A.; Santos, M. F. P.; Guimarães, R. C. L.; Dressler, V. L.; Flores, E. M. M.; J. Chromatogr., A 2008, 1213, 249.

47. Huang, M. D.; Krivan, V.; Fresenius J. Anal. Chem. 2000, 368, 227.

Submitted: December 31, 2010 Published online: February 10, 2011

FAPESP has sponsored the publication of this article. 


\title{
Supplementary Information
}

\section{Determination of Metal Impurities in Carbon Nanotubes by Direct Solid Sampling Electrothermal Atomic Absorption Spectrometry}

\author{
Paola A. Mello, Luiz Frederico Rodrigues, Matheus A. G. Nunes, Julio Cezar P. Mattos, \\ Edson I. Müller, Valderi L. Dressler and Erico M. M. Flores*
}

Departamento de Química, Universidade Federal de Santa Maria, 97105-900 Santa Maria-RS, Brazil and Instituto Nacional de Ciência e Tecnologia de Bioanalítica, Campinas-SP, Brazil

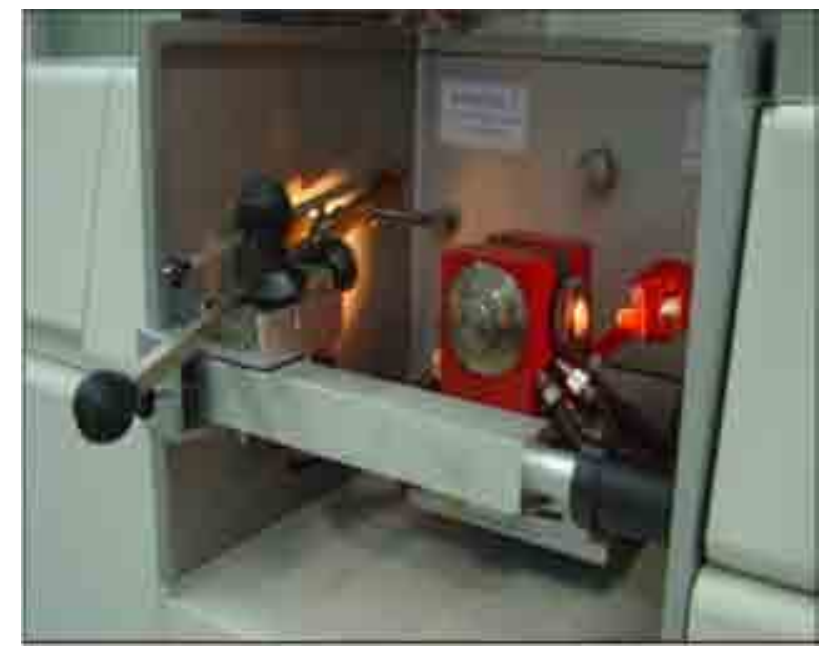

Figure S1. In detail, atomic absorption spectrometer (Model AAS 5 EA, Analytik Jena, Germany) showing the manual sample introduction system (Model SSA 5) for DSS-ET AAS, during atomization step $\left(2500^{\circ} \mathrm{C}\right)$ used for determination of metal impurities in carbon nanotubes.

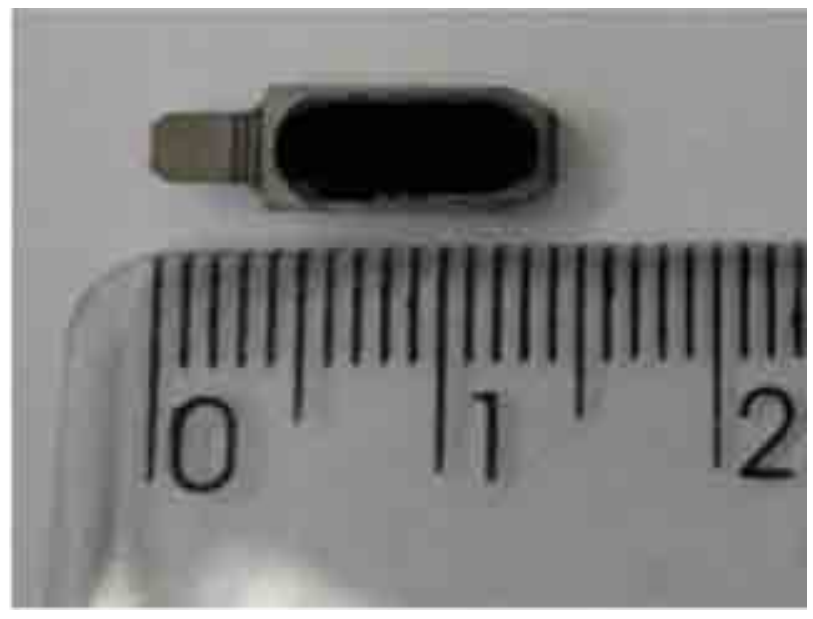

Figure S2. Carbon nanotube sample (about $7 \mathrm{mg}$ ) weighed onto sample platform before DSS-ET AAS heating program.

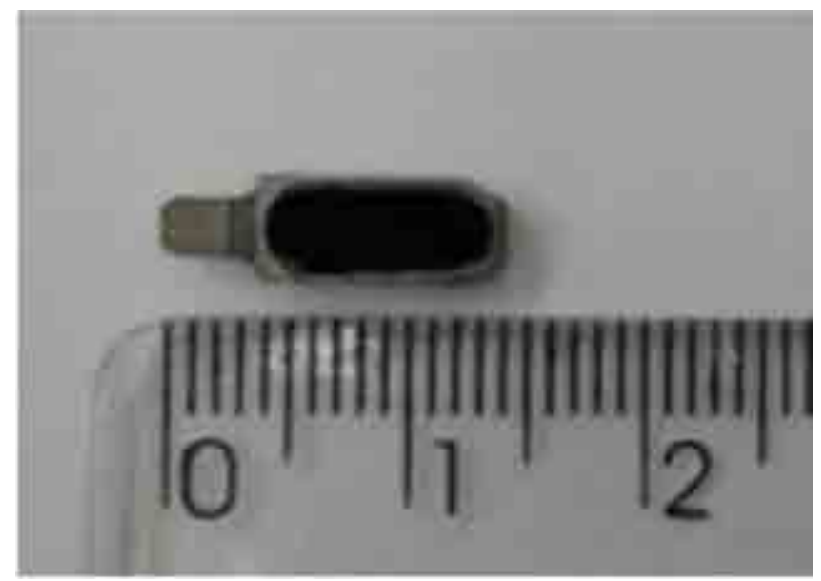

Figure S3. Aspect of graphite platform after DSS-ET AAS heating program for CNT: drying at $130^{\circ} \mathrm{C}\left(30 \mathrm{~s}\right.$, heating rate of $10{ }^{\circ} \mathrm{C} \mathrm{s}^{-1}$, argon flow-rate $\left.0.5 \mathrm{~L} \mathrm{~min}^{-1}\right)$, pyrolysis at $1400{ }^{\circ} \mathrm{C}\left(30 \mathrm{~s}\right.$, heating rate of $50^{\circ} \mathrm{C} \mathrm{s}^{-1}$, argon flow-rate $\left.0.5 \mathrm{~L} \mathrm{~min}^{-1}\right)$, atomization at $2500{ }^{\circ} \mathrm{C}(10 \mathrm{~s}$, heating rate of $3000{ }^{\circ} \mathrm{C} \mathrm{s}^{-1}$, argon flow-rate $0.5 \mathrm{~L} \mathrm{~min}^{-1}$ ). After heating program the mass losses were below $2 \%$. 